\title{
Emotional Deficiency in Web-based Teaching Environment and Its Solving Strategies
}

\author{
Jie Shui-Ping
}

Education College of Jianghan University, Wuhan, China

\begin{abstract}
In china, developing rapidly in Internet teaching exits serious lack of affection. This article aims to analyze the features on the lack of affection, reveal the causes of it and try to give corresponding solutions. The results indicate that lack of affection have manifested themselves mainly on lacking affinity for the resources of the network courses, being deficient in emotional information in virtual communication, being careless with emotional communication, the commercialized relations between teachers and students, and the lack of positive emotion. The main reasons that bring about the lack of affection are the impact of traditional education which pays more attention on intellectual education instead of affective education, the difficulties of design of teaching in affective domain, the inadequacy of role transition of teachers, the defects of Internet environment, the inadequacy of interaction in network teaching. At last, based on the perspective of teachers, students, and study resources, corresponding solutions on the lack of affection are given.
\end{abstract}

Index Terms: Web-based teaching environment; emotional deficiency; solving strategies

(C) 2012 Published by MECS Publisher. Selection and/or peer review under responsibility of the International Conference on E-Business System and Education Technology

\section{Introduction}

Since 1998, four universities have been approved as demonstration pilot project by the Ministry of Education to develop the distance education, 69 universities have been built network institutions whose students size has been more than three million until now. Meanwhile, many universities lent all-out support to the running of excellent courses, the usage of digital recourses and the development of teaching activities. Expectedly, online causes will become a common form of teaching in higher education and even play an increasingly important role in the long-life education system.

However, certain problems still exist on the online courses, especially for the emotional deficiencies which have caught the attentions of many western scholars [1-6]. The outlook of emotional deficiencies of promising online courses is worrying in China [7-9]. Paying attention on the lack of affection in internet education must be done without delay. The paper discusses the indicators of emotional deficiency in online courses, the factors of 
causing it, and the approaches on coping with it. It's expected that these results will facilitate to the development of online courses in China.

\section{The appearances of emotional deficiency}

\section{A. The lacking of affinity in online courses}

The original multimedia network teaching is frequently transformed into copying textbooks or electronic courseware by teachers. And many teachers give their lessons merely by some boring literal resources rather than by the interesting video or the cases relevant to what they need to teach. Therefore, online courses which should be full of the expression of emotion become sorts of teaching activities which is quite mechanical and unfriendly. And for these students taking online courses can only get the information from these boring words, similar to reading books, rarely from these vivid performances by teachers.

\section{B. The lacking of affective interaction in online courses}

In online courses, teachers and students can hardly communicate efficiently without certain facial expression, speech expression, or body expression, which leads to the losses of certain emotional information among these students and teachers. Therefore, these students are less likely to get the attentions from their teachers, and will feel confused and even become sluggish in these lessons; while for teachers, it's difficult to understand the feeling of their students and to control these lessons as well. Moreover, many teachers of online courses get their feedback by these comments in BBS or through email; however, these approaches can hardly provide this immediate information actually, thus posing some problems such as the decreasing interest of these students in learning and less number of students participating teaching activities in online courses.

\section{The replacing of affective interaction by games in online courses}

To some degree, the virtual nature of internet makes people lose their feelings of real life, the reality sense, and the judgments in daily life. To the medical students, their training of surgery, under virtual surgery system, seems to be a sort of game; for instance, these students can take one practice for many times and are allowed to make some mistakes in the practice as well, so that they can get certain improvements of their skills in some aspects of operations. However, in these processes of training, there are some problems actually neglected by people. When in the real situation of surgery, these students would get fear at first, especially when facing these strange situations and people, and when having the smells of blood and of scorched flavor which can hardly be found in the virtual surgery system. While getting familiar with all these surroundings, they will perhaps equate all these with the situations in the virtual surgery system; unfortunately, for these doctors, mistakes are never allowed in these operations any longer, and they bear these responsibilities toward these patients' families and the respects of life.

\section{The establishment of business relationship between students and teachers}

The online courses, affected by the commercialization in China, rarely set a goal of spreading the knowledge to students, but they have an aim of getting profits from these students. The courses given by teachers are like the commodities sold to students, and these students, similar to the customers, buy these courses from these teachers. In this case, these online courses actually offer a channel to conducting the trade of exchanging information for students and teachers. Thus, these students or teachers are more likely to treat these online courses as a way to gain knowledge or money, without any affection interaction.

\section{E. The lacking of positive emotion experience}

Comparing to those who join traditional courses in universities or colleges, the students, taking lessons online, are more likely to feel lonely and depressed [8]. Since such students have little chance to communicate with their classmates and teachers, they seem more urgent to get the courage from these classmates and teachers to some 
degree. Therefore, if not meeting such needs, these students would complain that they can hardly have connections with their teachers immediately when getting some problems in lessons.

For these teachers of the online courses, most lack the sense of professional self-efficacy. These teachers need the feedbacks and affirmations which are difficult to get from the students taking online courses. Thus, many teachers see the teaching in online courses as their part-time job, and rarely have communication with these students actively; on the other hand, some teachers, although willing to communicate with students, can hardly do it efficiently because of some certain limitations of the online courses, which actually creates the difficulty for teachers to get the affirmation from students.

\section{The reasons of emotional deficiency in online courses}

\section{F. The effect of the traditional courses}

Neglecting the importance of fostering affection between the teachers and students, intellectualism actually brings a dramatic effect on the developing of tradition education. In China, many educators still keep in favor of the aspects of the traditional education by solely emphasizing the development of students' cognition. In searching the information on the program descriptions of the online courses offered by many universities or colleges, we find that most set their goals of conveying the knowledge to students and developing their certain skills, rather than of cultivating the development of students' emotions.

\section{G. The difficulty of Affective Education}

Affective education is difficult to devise and to provide, since it has rarely a precisely agreed-on definition and it also involves too much information to measure correctly. Comparing to the maturely developed system of the knowledge and skill educating, affective education obviously needs a long-term development because it lacks a systematic and scientific plan of teaching. Thus, the difficulty of the affective education results in the abandoning of such education and in the unduly emphasizing of the education of cognition.

\section{H. The insufficiency of role switching}

In the online courses, there is a dramatic change in the relationship between teachers and students; the role of teachers, nowadays, is the designer of resources in education, the supervisor to these students' studying, and the persons of caring the development of these students' emotions. Unfortunately, the role switching, in fact, meets some troubles in reality teaching that many teachers still hold their old roles and refuse to the new expected role, since they are so afraid and anxious for the new information technology that they refuse to approach to internet, to master the fundamental knowledge about computer, and to communicate with their students online. Such insufficiency of role switching, therefore, leads to the loss of affective interaction between students and teachers.

\section{The limitation inherent in the network}

The virtuality, anonymity, openness, and interaction of Internet, on one side, bring people a convenient and efficient way to communicate, however, put them in the trouble of lacking the affective interaction in communications on the other side. For instance, the virtual nature of the internet, is likely to lead to the fear and irresponsibility of students to the reality, and negatively affect their cognition of life and nature, which is forming a mechanical way to treat others and themselves. Moreover, the anonymity of the internet will bring to people a sort of illusions that will result in the forming of double personality, and even will make some individuals evade the reality and develop certain behaviors damaging the society. For the openness of the internet, it enhances the difficulty to create an agreed-on criterion about the morality and behavior, which causes some behaviors breaking the roles of moralities and laws. And the interactive nature of the internet perhaps will contribute to the decreasing social activities and impede the development of people's interpersonal relation, which is making people feel withdrawal, lonely, and even depressed, since they can hardly get the feedback of others' emotions and attitudes from the real social interaction. In this sense, while enjoying the pleasure brought from the internet, we can never avoid to the virtual feeling and indifferent growing from the internet. 


\section{J. The insufficiency of interaction in online courses}

Although there are many ways of interacting in online courses, these ways unfortunately are far from an efficient approach as we expected [10]. In the development of online courses, the interactive techniques are overly emphasized and the demand, of teaching in online courses, is neglected. In the reality, actually, overemphasis of the interactive function of media can rarely improve the quality of teaching in online courses. Furthermore, the online courses lacking of the interactive function cannot bring the help in the students in the fact.

\section{The way of solving emotional deficiency}

Students, teachers, and the resources are three components, indispensable and interdependent, of the affective interaction between students and teachers. Therefore, to solve the problems inherent in these three parts will become the curical point to overcome the problem of emotional deficiency, and even to improve the quality of affective interaction.

\section{K. The factor of teacher}

\section{1) Developing the training program for teacher}

Teachers need the training, offered by university or colleges, to master the fundamental skills of teaching online. In this training program, they will accept the courses about the morality of teachers, the concept of teaching, and the guiding of how to use internet; among these three parts, the last one is most important actually. And the training program can be run in several ways of giving lessons, discussing, imitating, or introspecting.

\section{2) Building the website or blog for teacher}

Teachers can post the information, about their background, their interest, and their experience of studying, on their own blog so that they can be closer to their students. Moreover, they can assign the homework and put their teaching program on their blog; in this way, teachers can efficiently communicate with their students by commenting on the blog, thus developing a good way to share their thoughts with the students.

\section{3) Understanding students}

Teachers of online courses can get the information about their students' background and personality in such way as reading the blogs and documents of students, discussing by commenting online, chatting face to face, and chatting online, so that teachers can develop certain study resources to meet the demand of these students of different characteristic, and to offer the help in their study and life.

\section{4) Making learning contracts with students}

Learning contract, created by students and teachers, is a sort of standard obeyed by all members involving in the online courses. Every member has to create their own account, to reach the agreement in the learning contracts, and to obey all their roles. These members have responsibilities to all the results caused by them. In such surrounding without the external threat, all the members can cooperate, communicate, and share their thoughts with each other, which can efficiently help those to overcome the lonely feeling coursed by the internet. Moreover, learning contract calls for the cooperating, discussing, role playing, and obeying principles online, which guarantees everyone has chance to participate in a discussion, and meanwhile avoids to rudely interrupting and to deviating from the topic.

\section{5) Offering good support service}

In online courses, teachers have the duty to guide their students to learn how to study, how to conduct proper behaviors, and how to control their emotions, which facilitates to controlling teaching, and to improve the relationship between teachers and students.

a) Guiding students to learn knowledge by themselves. Generally, this process includes entrance education, the introduction to the subjects offered in these courses, and the guidance to students to learn to make their own plan of studying and to use the computer in online courses. 
b) Offering certain helps for students. Teachers help students to solve some problems immediately on phone or email.

c) Offering immediate feedback. In checking students' homework, teachers give students quick feedbacks and some positive suggestions that will contribute to students' rapid improvement in their study.

d) Establishing forum of online courses. Students can share their information and discuss some problems, thereby fostering their feeling of belonging.

e) Providing the activities participated by all students. In these activities, students can get chances to communicate with others face to face, which associate online teaching with classroom teaching.

\section{Factor of students}

1) Preparing for the lessons

Before classes, students have to know curriculum Aims and the fundamental skills required in these lessons so that they can ensure that they finish all these classes in time, and that their equipments can meet the demand of these online courses. And if they meet some problem, they need to know how to get help in online courses.

\section{2) Improving the skills of studying online}

a) Getting skills of gaining information and dealing with it. Learning how to get and select information from online resources, books, magazines, and newspapers.

b) Improving skills of communicating online. Increasing the capacity of communicating clearly and correctly on email, forum, and real-time interaction.

c) Having the ability of self-control. Making suitable schedule of studying, students need to how to use their time properly and efficiently. By online testing, they will get the comments from other students and teachers and will evaluate themselves so that they can control the situation of their studying.

3) Studying actively in the online courses

Students need a attitude of studying actively in the online courses, for instance, preparing lessons before having class, seeking for help from teachers actively, sharing information and emotions with teachers and students, participating the discussion by offering your thoughts, and caring other students in the online courses.

\section{Factor of resources}

1) Making clear emotional goals of online courses

By employing the descriptive language into the content of training emotional aims, the online courses should take the emotional aims as an important part of online teaching. Promoting emotional development also can be quantized in the forms of style and frequency of activities.

2) Emphasizing the devising of website of online courses

The pages of online courses are the channels for students to get information. Well-devised website will make students feel relaxed and interesting, thus contributing to their focus in the study and the communication between others. In the development of website of online courses, a unifying, clear style is preferred, and moreover, the visual appearance and usage need to match properly.

\section{3) Creating situational studying resources}

a) Teachers' full understanding of students' preparation should be sufficiently. By analyzing the construe of cognition, learning motive, experiences, emotional factors, teachers have to decide what to teach in view of students, and then determine the type of situational studying and use the proper media to bear it.

b) Teachers should be adroit in using media technique. When creating cognitive condition, teachers can employ media techniques to present real problems to the students vividly by taking the advantage of pictures, words, audios, and videos, thereby making the content more concrete and appreciable in order to arouse students' curiosity and to develop their ability of solving problems. 
c) Learning resources with a conversational style should created. When creating the studying resources, teachers' role of guiding students is needed to be considered so that the students will consider that they were guided by teachers when studying these resources alone. In this way, surely, students will have a comfortable feeling with these resources.

d) Virtual reality technology should be employed. The virtual reality technology has the characteristic of immersion, interaction, and imagination. This technology offers people an entirely new way to study by providing a virtual environment full of knowledge and emotion [11].

\section{Conclusion}

In the period of transition -- traditional education to online education, web-based teaching is causing the materialized environment of human nature and emotional deficiency objectively. Actually, online teaching should create a humanistic environment to offset the loss of affection in online courses. However, under the environment of internet, emotional teaching is a complex task, involving pedagogy, educational psychology, technology philosophy, instructional design, multimedia technology, computer network technology, intelligent interactive technology, affection computing technology [12], and virtual reality technology. In order to study the humanity in online education, understanding the relation between the humanity of online education and these technologies and theories is needed with the approach of creating the suitable hardware and software, establishing the studying resources and environment, and training teachers' skills of teaching.

\section{References}

[1] N. Hara, "Student distress with a web-based distance education course", Journal of Information, Communication \& Society, Vol. $\underline{3}$, No.4, pp557-579, 2000.

[2] M. Herczeg, "Experience design for computer-based learning system: learning with engagement and emotions", 2004, from http://scholar.google.com.hk.

[3] K. C. Ng, "Using e-mail to foster collaboration in distance education", Journal of Open and Distance Learning, Vol.16, No.2, pp191-200, 2001.

[4] D. T. Schaller, S. Allison-Bunnell, M. Borun, and M. B. Chambers, "How do you like to learn? comparing user preferences and visit length of educational web sites", 2002, from http://www.eduweb.com/

[5] R. Wegerif, "The social dimension of asynchronous learning networks", Journal of Asynchronous Learning Networks, Vol.2, No.1, pp34-49, 1998.

[6] K. O’Regan, "Emotion and e-learning", Journal of Asynchronous Learning Networks, Vol. 7, No. 3, pp.78-92, 2003.

[7] H. W. Luo, Y. M. Wang, and Z. T. Zhu, "Research on emotional deficiency in the multimedia learning system of Open English", Journal of Open Education Research, Vol.14, No.3, pp74-78, 2008 (In Chinese).

[8] X. H. Xu, "Study on strategy of the problem of emotional communication in Web-based instruction", master degree thesis, from www.cnki.com, 2010 (In Chinese).

[9] B. Wu, "Research of emotional interaction strategies in Web-based curriculum", master degree thesis, from www.cnki.com, 2007 (In Chinese).

[10] G. Y. Zhang, J. Y. Hu, "Scarcity of Emotional Exchanges in Web-based Teaching Environment and Its Solving Strategies", Journal of Modern Educational Technology, Vol.15, No.1, pp.15-20, 2005 (In Chinese).

[11]H. Q. Zhao, and B. Sun, "Construction of emotional learning environment based on virtual reality in network environment”, Journal of China Educational Technology, No.4, pp101-104, 2009 (In Chinese).

[12] R. W. Picard, Affective Computing. Boston: MIT Press, 2000. 